\title{
A SYSTEMATIC LITERATURE REVIEW OF RISK AND GENDER RESEARCH IN TOURISM
}

\author{
Elaine Chiao Ling YANG ${ }^{\mathrm{a}}$ \\ elaine.yang@griffithuni.edu.au \\ Catheryn KHOO-LATTIMORE \\ c.khoo-lattimore@griffith.edu.au \\ Charles ARCODIA ${ }^{\mathrm{a}}$ \\ c.arcodia@griffith.edu.au \\ ${ }^{\text {a }}$ Griffith Business School \\ Department of Tourism, Sport and Hotel Management \\ Nathan Campus, Griffith University \\ 170 Kessels Road, Nathan \\ Brisbane, Queensland 4111, Australia
}

Corresponding author: Elaine C. L. Yang

\section{Acknowledgement}

The Version of Record of this manuscript has been published and is available in Tourism Management since 22 October 2016.

URL: http://www.sciencedirect.com/science/article/pii/S0261517716301893

DOI: 10.1016/j.tourman.2016.10.011 


\begin{abstract}
Resonating with a growing sense of uncertainty recently, an increasing number of studies have been dedicated to travel risk because risk and tourism are intrinsically connected. However, existing tourism risk literature was criticized for lacking theoretical foundations, which has resulted in fragmented understandings, including contradictory opinions regarding the effect of gender on risk perception. In response to these criticisms, this study systematically investigates tourism risk literature from a gender perspective, with an aim to map out what is known about the gendered travel risk and what needs to be explored further. The review findings suggest that a majority of existing risk and gender studies have prioritized the experience of Western travelers. The findings indicate a lack of a gender- and risk-focused investigation and theoretical framework, and a dearth of an interpretive and reflexive approach. A plethora of evidence of gender difference in tourist risk experience has been identified.
\end{abstract}

Keywords: Risk; Gender; Tourism; Systematic Quantitative Literature Review 


\section{INTRODUCTION}

\subsection{The Growing Awareness of Risk in Tourism}

Rapid modernization and secularization have taken place since the end of World War II, and have led to substantial changes in labor division, family structure, and gender norms (Lupton, 2013). These unprecedented social transformations portray the questioning and breakdown of traditions and grand ideologies promised in early modernity and have resulted in the decline of trust and social cohesion (Giddens, 1991). Reflecting the growing sense of uncertainty and insecurity emerging against this social background, Beck (2006) dubbed the contemporary society as the risk society. Indeed, the term "risk" has been increasingly incorporated in contemporary linguistic structure; "risk" has become a widely quoted term in scholarly research, mass media, and everyday life (Lupton, 2013). A similar situation is found in the field of tourism, where the growing presence of tourist risk research is observed. This growth has been most noticeable after the $9 / 11$ terrorist attack in 2001 , followed by a myriad of tragic incidents at both global and regional scales, such as the SARS outbreak in 2003, Indian ocean tsunami in 2004, Arab Spring uprisings in 2010, and the recent Paris attacks in 2015 and Istanbul Atatürk airport attack in 2016. These incidents have all caused severe impact on international and regional tourism (Avraham, 2015; Kovari \& Zimanyi, 2011; Mullen, 2016; Newton-Small, 2015). Since then, tourism scholars have recognized the impact of risk perception on travel behavior and decision, because tourists are likely to avoid destinations with greater perceived risk (Kozak, Crotts, \& Law, 2007).

\subsubsection{The Intricate Relationship between Risk and Tourism}

Risk and tourism are inseparable, because the decision to travel itself implies risk and uncertainty, as it involves corporeal travel to unfamiliar places and social environments (Chang, 2009). In addition, tourism, resembling other service products, is intangible, 
inseparable, heterogeneous, and perishable, which renders risk an essential aspect of the tourist experience (Mitchell \& Greatorex, 1993; Williams \& Baláž, 2013). In certain tourism settings, risk contributes to the sense of excitement and adventurousness in travel experience (Cater, 2006; Dickson \& Dolnicar, 2004; Quintal, Lee, \& Soutar, 2010).

\subsubsection{Problems with Existing Risk Research in Tourism}

Considering the relevance and influence of risk on tourists and the industry, a considerable body of tourism risk literature has been developed, especially in the past two decades (Yang \& Nair, 2015). Nevertheless, a systematic review of risk literature in tourism is absent, which is indicated in Noel Scott's consolidated list of review papers in tourism posted on 3 March 2015 on TRINET ${ }^{1}$. Along with the development of this tourism sub-field, a criticism arises in relation to the lack of a theoretical framework in tourism risk research, which has resulted in fragmented, inconsistent, and superficial understandings of tourist risk experience (Korstanje, 2009; Williams \& Baláž, 2013). One of the issues noted is the contradictory opinions regarding the influence of gender on travel risk (Yang, Sharif, \& Khoo-Lattimore, 2015). One school of thought is of the opinion that the influence of gender on travel risk is insignificant because risk is mediated by many other factors besides gender, such as tourist role and cultural background (Carr, 2001; Lepp \& Gibson, 2003). On the contrary, other scholars have argued that travel risk is essentially gendered (Elsrud, 2001; Gustafson, 1998).

\subsection{The Influence of Gender on Risk and Tourism}

\subsubsection{The Gendered Risk}

Gustafson (1998) suggests that women and men may perceive risk differently because some risks are imposed on women by men, such as the risk of sexual violence, which is a

\footnotetext{
${ }^{1}$ TRINET is an online discussion group that connects international tourism research and education community.
} 
manifestation of male dominance over women. Adding to this understanding of the gendered risk perception, other scholars demonstrate how risk-taking behavior is received differently by society as far as gender is concerned. In general, women's risk-taking behavior is more likely to be negatively evaluated compared to men's, because risk taking is associated with the construction of masculinity, whereas risk aversion is a desirable value of femininity (Elsrud, 2001; Laurendeau, 2008; Olstead, 2011). Prior tourism research has lent support to this interpretation of the gendered risk. For instance, in the realm of adventure tourism, Elsrud (2001) investigates the negative connotation associated with adventurous women or the adventuresses. The value-laden connotation is indicated in a number of English dictionaries which define adventuress as "fem. adven'turess (chiefly in bad sense)" (Elsrud, 2001, p. 614) or "a woman who seeks social or financial advancement by dishonest or unscrupulous methods" (Oxford Dictionaries, 2016). Elsrud's (2001) argument is further supported by empirical data, which reveal the dilemma that female adventure tourists face in their gender identity constructions because their risk-taking behavior is inconsistent with the social expectations of femininity. Essentially, what is considered as a risk in one society may be perceived differently in another (Green \& Singleton, 2006; Lupton, 2013).

\subsubsection{The Gendered Tourism Space}

A number of studies reveal gender differences in tourist risk perception and risk-taking behavior. Specifically, female tourists were found to be more sensitive and vulnerable to certain types of risk, such as physical risk (e.g., sexual harassment and assault), when using the tourism space (Kozak et al., 2007; Lepp \& Gibson, 2003; Park \& Reisinger, 2010; Qi, Gibson, \& Zhang, 2009), a space which has been identified as gendered and sexualized (Pritchard \& Morgan, 2000). From a historical perspective, tourism has a masculine origin when the term, "tourist" became increasingly prominent in the mid- $18^{\text {th }}$ century (Graburn \& 
Jafari, 1991). A tourist used to denote a person who explores the exotic unknown for pleasure and excitement, which accords with the characteristics of masculinity (Enloe, 1989). Although women's participation in tourism is now comparable to men (Harris \& Wilson, 2007), the contemporary tourism space is still subject to criticisms for being highly masculinized and privileging men's travel experiences, which are reflected in sex tourism and tourism advertisements where female bodies are commonly objectified and sexualized (Pritchard \& Morgan, 2000; Wilson \& Little, 2008). Furthermore, the tourism space is often imbued with sexual implications and sexual permissiveness due to its perceived liminality (Jordan \& Gibson, 2005; Reichel, Fuchs, \& Uriely, 2007; Wilson \& Little, 2005). Therefore, when female travelers wander in this masculinized and sexualized space, their bodies are subjected to a certain degree of gender-induced risk.

\subsection{Aims and Significance of the Review}

In response to the growing awareness of risk in tourism, the inconsistent opinions of the influence of gender on travel risk, and the intricate relationship among risk, tourism, and gender, this study sets out to review existing tourism risk literature from a gender perspective. Specifically, this study systematically investigates and synthesizes the extant literature concerning travel risk and gender, with an aim to map out what is known about the gendered travel risk and what needs to be explored further. The review investigates how risk has been studied in prior research in terms of the research topic, type of risk, research method, and theoretical framework. The context, sample, and geographical location of the research are also considered. More importantly, this review analyzes the gender difference/similarity in tourist risk perception and risk-taking behavior reported in the extant literature, and the explanations provided. By doing so, this review addresses the incongruent opinions voiced in 
past studies. An agenda for future research is then proposed based on the issues identified in the review.

The significance of this review is threefold: First, despite the fact that the impact of risk on tourism has been widely recognized, a systematic review of risk literature in tourism is long overdue. Hence, this review is timely in contributing to the knowledge void. In particular, it provides an overview of the development and landscape of travel risk literature from a gender perspective. By mapping what is known, this review lays the groundworks, and identifies gaps and opportunities for future research to build upon. Second, this review advances existing understanding of gender and risk respectively, as well as a synergy between the two in the field of tourism. Despite the inconsistent views concerning gender and travel risk, the significance of risk on women's travel experience is articulated or inferred in many women-focused tourism studies (Elsrud, 2001; Wilson \& Little, 2008), and is listed in the top ten most researched topics ${ }^{2}$ in a recent review of tourism gender research (FigueroaDomecq, Pritchard, Segovia-Pérez, Morgan, \& Villacé-Molinero, 2015). This review seeks to contribute to this stream of research. Third, as a result of women's increasing participation in the workforce and the consequential financial independence and spending power, the rise of the female travel market across the globe is indisputable (Bond, 2015). In response to this trend, gender research in tourism has gained increasing momentum in recent years with a growing number of tourism researchers working and writing on gender issues (see KhooLattimore \& Mura, 2016; Khoo-Lattimore \& Wilson, 2016; Figueroa-Domecq et al, 2015). By tapping into the gender and risk literature, this review casts light on the industry catering

\footnotetext{
${ }^{2}$ According to Figueroa-Domecq et al. (2015), the top 10 most researched topics on gender and tourist include: consumer behavior; decision-making and motivation; sex/romance tourism; rural tourism and ecotourism; perceptions of tourism destination and product images; market segmentation and marketing; risk perception; medical, cosmetic and reproductive tourism; gay, lesbian and transsexual tourism; tourist typologies; and tourist experiences.
} 
to the female travel market. Figure 1 summarizes some of the trends of and issues with risk and gender research in tourism as well as the aims of the current study.

Figure 1. Review Aims

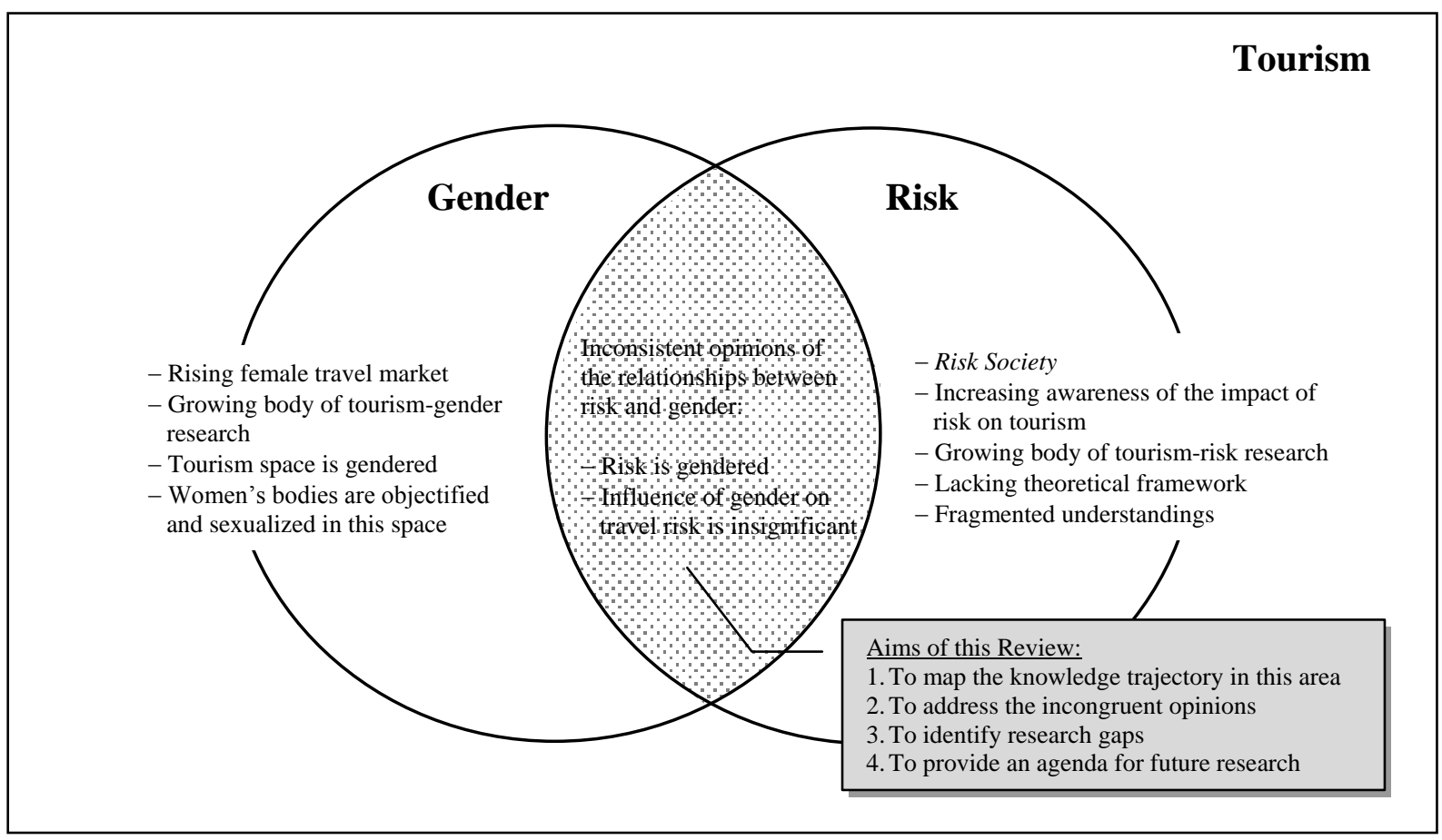

\section{METHODOLOGY}

\subsection{The Method - Systematic Quantitative Literature Review}

There are a number of established as well as emerging methods to conduct a literature review, which can be broadly categorized into the meta-analysis, traditional narrative review, and systematic quantitative review (Pickering \& Byrne, 2014). Meta-analysis primarily focuses on the statistical analysis of findings from prior research and often involves data conversion and complex statistical procedures. Meta-analysis is effective where the extracted studies have comparable research designs (Mays, Pope, \& Popay, 2005; Pickering \& Byrne, 2014), which is not the case in this study. In contrast, a traditional narrative review is less rigid, but some scholars argue that this very characteristic renders the method more malleable and 
hence comprehensive (Mays et al., 2005). Due to the narrative feature of traditional review, findings from prior studies are discussed but rarely synthesized and quantified to demonstrate patterns, which defeats the purpose of this study. This study employed a systematic quantitative approach to map and review existing tourist studies concerning risk and gender. A systematic quantitative literature review differentiates from a traditional narrative review in various aspects. This approach emphasizes a systematic process to the literature search, extraction, and synthesis, which is articulated and justified in the reporting. To enhance the quality of the reporting and the traceability of the process, a reporting flowchart (see Figure 3) is recommended to register the number of studies included and excluded at different stages of the literature search; this practice is not common in a traditional literature review. Besides, a systematic and quantitative approach to review is feasible in mapping the landscape and boundary of knowledge by counting and charting what is known and thus, sheds light on what is yet to be known (Pickering, Grignon, Steven, Guitart, \& Byrne, 2015). A systematic quantitative review is comprehensive because it can synthesize a sizeable and heterogeneous collection of interdisciplinary research, conducted in different settings, using various research designs (Pickering \& Byrne, 2014). As the interest of this review lies in mapping the landscape of research concerning travel risk and gender, which involves multi- and interdisciplinary literature from the fields of tourism, feminist/gender studies, and risk research, a systematic quantitative approach is deemed an appropriate tool.

\subsection{The Systematic Review Process}

Figure 2 exhibits the systematic review process undertaken in this study, which was adapted from Petticrew and Roberts (2006) and Pickering and Byrne (2014). The first author attended a workshop in person on the systematic literature review technique conducted by Pickering herself. The review began by delineating the review aims and objectives, which have been 
detailed in the preceding section. Based on the review aims, a review protocol was developed to guide the literature search; it contained information of the search terms, databases, and screening criteria. To capture research that has investigated tourist risk perception from a gender perspective, "risk", "tourism or travel or tourist", and "female or woman or gender" were used as the search terms. The gender search terms were informed by prior reviews of gender in tourism (Figueroa-Domecq et al., 2015) and leisure studies (Henderson \& Gibson, 2013). The emphasis on female was supported by seminal gender literature which suggests that there is only one gender that is the feminine, because the masculine is the general (Wittig, 1983; Butler, 1990). This is also reflected in the development of gender literature in tourism. Before the 1980s, women's perspectives were omitted from the tourism scholarship because men's views were regarded as the universal (Henderson \& Gibson, 2013).

Seven academic databases were identified from prior tourism review publications, which include EBSCO Host (Hospitality and Tourism Complete), Science Direct (Elsevier), Emerald, Scopus, Web of Science, ProQuest, and Sage (Durko \& Petrick, 2013; FigueroaDomecq et al., 2015; Gross, Gao, \& Huang, 2013; Mair, Ritchie, \& Walters, 2014; Yang \& Cheung, 2010). In this study, the literature search was conducted utilizing all seven databases to ensure comprehensiveness, while prior reviews normally considered two to three databases. To safeguard the quality of the review and to enable effective synthesis, only original research articles published in English-language peer-reviewed journals were considered. Hence, any research papers published in English-language academic journals that contained the aforementioned search terms in the title, abstract, or keywords were considered, and no timeframe was applied to the search. Additional filters were used in certain databases, such as Science Direct, Scopus, and Web of Science that provide options to limit the search within the social science discipline. 
Figure 2. Systematic Review Process

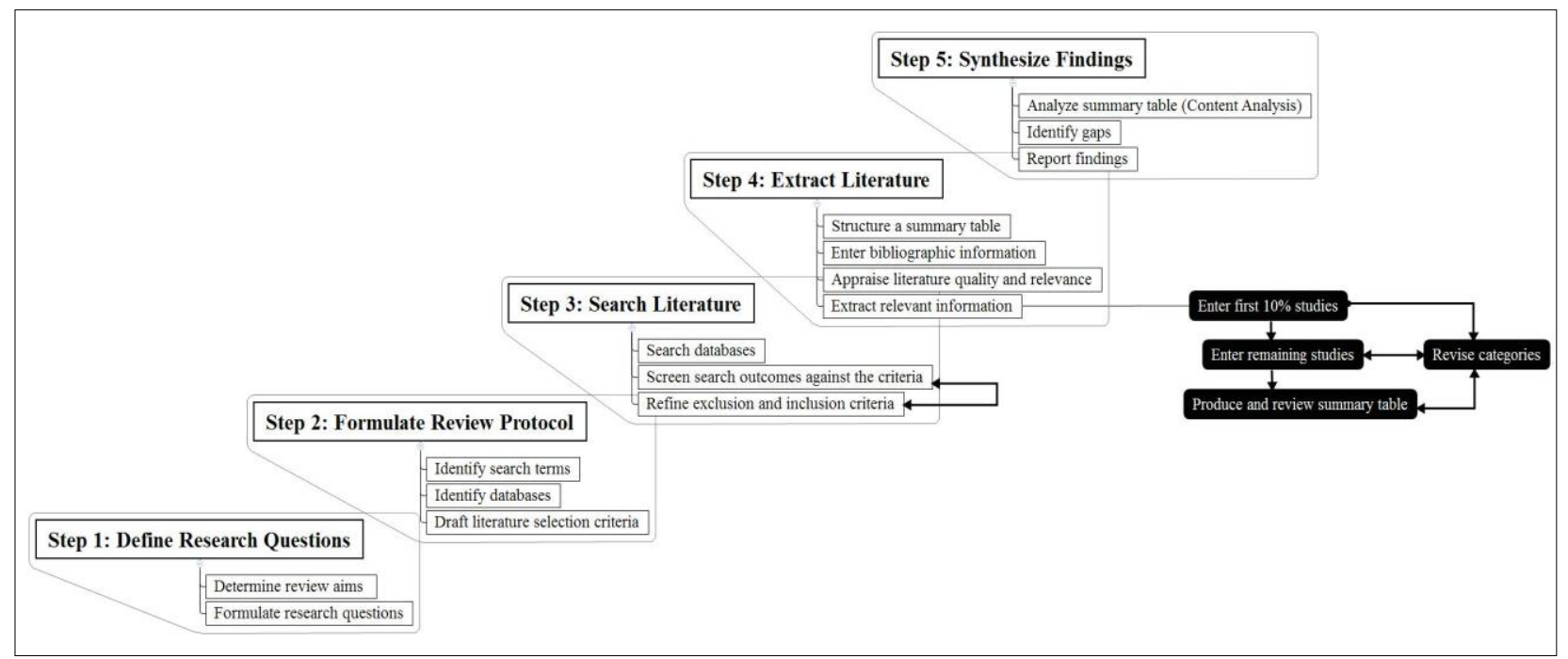

Source: Adapted from Pickering and Byrne (2014)

As of December 2015, the literature search against the seven databases resulted in 1723 records, which were exported to Endnote software for data management. After removing 279 duplicate references, the remaining 1444 records were screened against the literature selection criteria, where non-journal publications (e.g., book reviews, commentaries, editorial notes, conference papers, and book chapters) were eliminated. Publications from medical journals were removed because risk was investigated from a pathological perspective and the findings were intended for medical practitioners and researchers. Some exceptions were public health journals which are indexed under the social science discipline, and travel medicine journals which focus on travel-related health problems. To ensure consistency across databases, studies where the search terms did not appear in the "author-supplied keywords" but in the "indexed keywords" (e.g., Keywords Plus in Web of Science and Subject Terms in ProQuest and EBSCO Host) were also discarded. As the assessment progressed, further selection criteria were considered to exclude studies that focused on local community rather than tourists; investigated travel as in daily mobility and migration rather than tourism; referred to Travellers as an ethnic minority in 
Ireland; or mentioned "risk" but the subject of investigation was irrelevant to risk. The papers were assessed based on the abstracts, and full texts were referred to when necessary.

The screening process yielded 107 records, of which full texts were retrieved and further reviewed for eligibility to be included in the final analysis. Studies discarded at this stage were provided with justifications, where the most common concern lay in the research focus. Because risk is not an exclusively technical term and is a general expression, many studies mentioned risk throughout the text but the research itself has not investigated tourist risk perception or risk-taking behavior, nor has it considered risk as one of the parameters. For instance, Fernández, Pena-Boquete, and Pereira's (2009) abstract mentioned "the greater risk of gender discrimination" in a hospitality context. It was unclear whether gender-related risk was investigated in the paper; hence, the full-text was examined. A text search result showed that risk was mentioned again but only once in the context of the hospitality workers' perception of "being at risk of social exclusion" (p. 302) due to low-wage employment. Assessing the narratives of risk in these two instances, this paper was excluded from the review on the basis of not investigating travel risk. Another example is a slow tourism study by Foley (2015) where risk was mentioned in the abstract: "slow tourism risks becoming a source of conspicuous consumption". In this case, "risk" was used as a verb that is similar to the meaning of "endanger" rather than being investigated as an independent topic on its own. Therefore, Foley's (2015) study was excluded from the review. Similar instances were also found in a tourism gender study by Aitchison (2005) where risk was used as a general expression rather than being the research focus: "The article suggests that to disembody that which is not yet fully formed runs the risk of aborting rather than nurturing the embryonic project of advancing feminist and gender tourism studies." 
As a result, only 84 studies were identified as eligible, and the reference lists of these studies were cross-checked to identify papers that might have been overlooked. Two additional studies were identified, which resulted in 86 studies included in the final analysis. Figure 3 outlines the number of studies screened and excluded at different stages of the review. The reporting flowchart was in accordance with the guideline of Preferred Reporting Items for Systematic Reviews and Meta-Analyses (PRISMA) (Moher, Liberati, Tetzlaff, \& Altman, 2009), with minor adjustments to fit the study purpose.

Figure 3. A PRISMA Flowchart

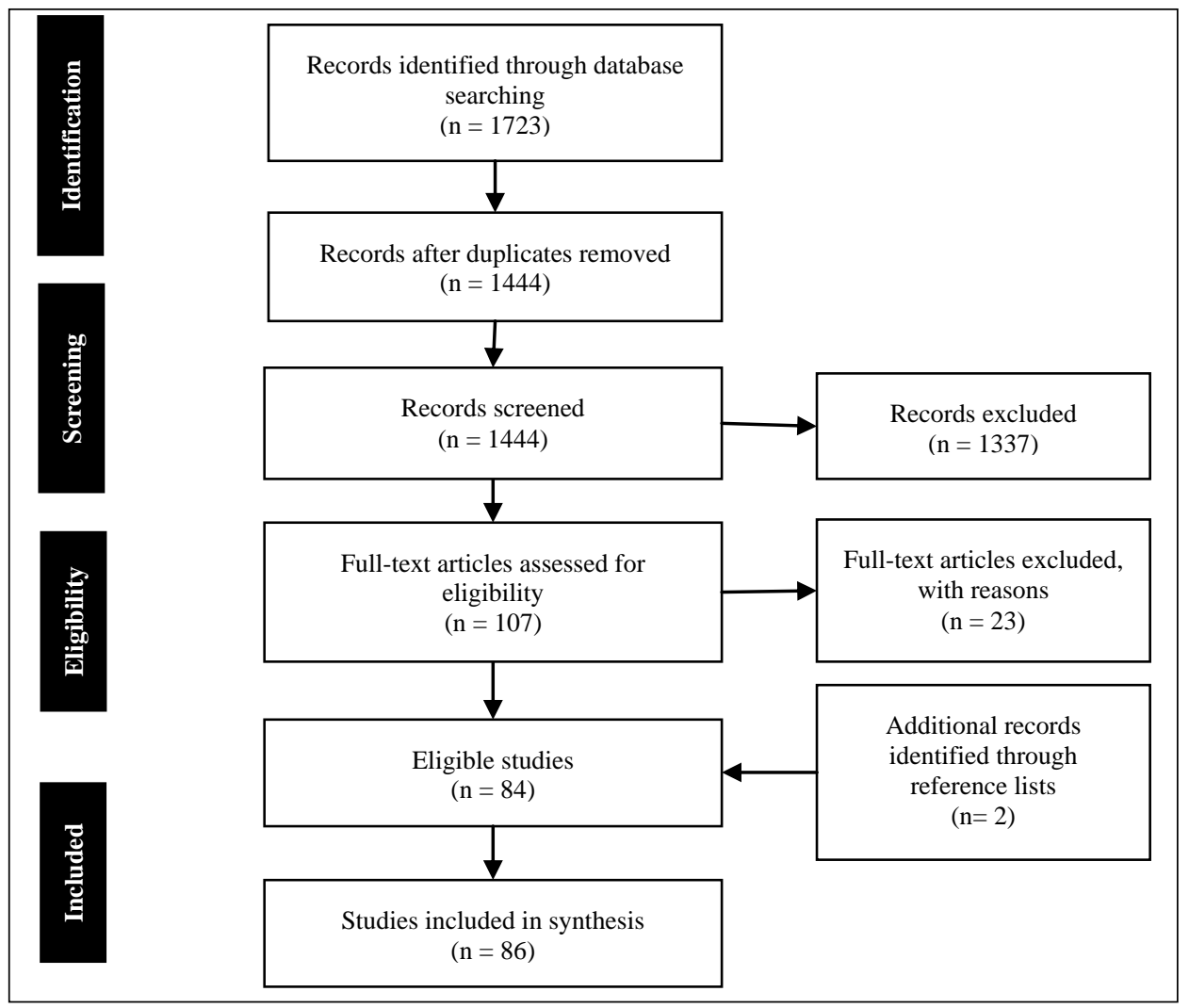

Source: Adapted from Moher et al. (2009)

A summary table was created in Microsoft Excel software, where the bibliographic details of the 86 studies were tabulated. The profiles of the extracted studies are depicted in 
Tables 1 and 2. As shown in Table 1, the number of research publications on risk and gender, especially in the field of tourism, has increased significantly since 2001. This trend is consistent with the overall development of risk research in tourism, as discussed in the introduction section. These studies were appraised and ranked according to quality and relevance to the interest of the review. Some evaluation considerations included: the extent to which the concept of risk was explored; the emphasis on gender; the presence of explanation for gender difference or uniformity in travel risk perception/behavior; and the methodological soundness. Subsequently, information regarding the research topics, research aims, risk typologies, fieldwork locations, samples, methodologies, gender-related findings, and explanations was extracted from each study and was recorded in the summary table. A content analysis was conducted on the summary table, where descriptive information within each category was coded, aggregated, and abstracted into constructs and themes. The patterns of themes were explored and quantified, with gaps identified and reported in the following section.

Table 1. Literature Profiles by Disciplines and Publication Years

\begin{tabular}{lcccccc}
\hline Disciplines (No. of Journals) & No. of & $1990-$ & $1996-$ & $2001-$ & $2006-$ & $2011-$ \\
& Studies & 1995 & 2000 & 2005 & 2010 & 2015 \\
\hline Tourism, Leisure, and Hospitality (25) & 40 & & 3 & 10 & 10 & 17 \\
Health (17) & 17 & 1 & 4 & 2 & 4 & 6 \\
Travel Medicine (3) & 11 & & & 1 & 6 & 4 \\
Business (General) (6) & 8 & & 2 & & 3 & 3 \\
Interdisciplinary (7) & 7 & 1 & & & 3 & 3 \\
Geography (1) & 1 & & & & & 1 \\
Sociology (1) & 1 & & & & 1 & \\
Women's Studies (1) & 1 & & & & & \\
Total & 86 & 2 & 9 & 13 & 28 & 34 \\
\hline
\end{tabular}


Table 2. Top Journals for Gender and Travel Risk Research

\begin{tabular}{lcc}
\hline Journals & No. of Studies & $\%$ \\
\hline Tourism Management & 7 & $8.1 \%$ \\
Journal of Travel Medicine & 5 & $5.8 \%$ \\
Travel Medicine and Infectious Disease & 4 & $4.7 \%$ \\
Annals of Tourism Research & 4 & $4.7 \%$ \\
Journal of Travel \& Tourism Marketing & 4 & $4.7 \%$ \\
Total & 24 & $28 \%$ \\
\hline
\end{tabular}

\section{REVIEW FINDINGS}

\subsection{Research Contexts and Topics}

Table 3 summarizes the tourist samples, geographical locations, and tourism settings considered in the extracted studies. Western tourists (44.2\%) were the most researched group, followed by multi-ethnic studies (20.9\%) conducted in the United States. A majority of the studies had fieldwork conducted in Europe and North America (58.2\%). Only 14 (16.3\%) studies were conducted in Asia, and only eight (9.3\%) have focused on Asian tourists; these studies were recent, mostly published within the last ten years. Several studies were conducted in Central and South America, Africa, and the Middle East but predominantly focused on Western and international tourist experience rather than people from those regions. The most common tourism setting concerned in prior research was international tourism (26.7\%), followed by sex and romance tourism (12.8\%), and adventure tourism $(7.0 \%)$. 
Table 3. Tourist Samples, Geographical Locations, and Tourism Settings

\begin{tabular}{|c|c|c|c|}
\hline & \multirow{2}{*}{$\begin{array}{l}\text { No. of } \\
\text { Studies }\end{array}$} & \multirow{2}{*}{$\%$} \\
\hline & & & \\
\hline \multirow[t]{7}{*}{ Tourist Samples } & Western Sample & 38 & $44.2 \%$ \\
\hline & Multi-ethnic Sample (research conducted in US) & 18 & $20.9 \%$ \\
\hline & International/Cross-cultural Sample & 12 & $14.0 \%$ \\
\hline & Asian Sample & 8 & $9.3 \%$ \\
\hline & Israeli Sample & 3 & $3.5 \%$ \\
\hline & Not Applicable (review and document analysis) & 4 & $4.7 \%$ \\
\hline & Not Specified & 3 & $3.5 \%$ \\
\hline \multirow[t]{9}{*}{ Geographical Locations } & Europe & 25 & $29.1 \%$ \\
\hline & North America & 25 & $29.1 \%$ \\
\hline & Asia & 14 & $16.3 \%$ \\
\hline & Central \& South America & 6 & $7.0 \%$ \\
\hline & Cross-cultural Context & 5 & $5.8 \%$ \\
\hline & South Pacific & 4 & $4.7 \%$ \\
\hline & Africa & 3 & $3.5 \%$ \\
\hline & Middle East & 2 & $2.3 \%$ \\
\hline & Not Specified & 2 & $2.3 \%$ \\
\hline \multirow[t]{9}{*}{ Tourism Settings } & International Tourism & 23 & $26.7 \%$ \\
\hline & Sex/Romance Tourism & 11 & $12.8 \%$ \\
\hline & Coastal Tourism & 9 & $10.5 \%$ \\
\hline & Adventure Tourism & 6 & $7.0 \%$ \\
\hline & Air Travel & 5 & $5.8 \%$ \\
\hline & Backpacking & 4 & $4.7 \%$ \\
\hline & Urban Tourism & 4 & $4.7 \%$ \\
\hline & Ski Tourism & 4 & $4.7 \%$ \\
\hline & Spring Break & 4 & $4.7 \%$ \\
\hline
\end{tabular}




\begin{tabular}{lllr}
\hline Mega Event & 3 & $3.5 \%$ \\
Casino Tourism & 3 & $3.5 \%$ \\
Hospitality & 2 & $2.3 \%$ \\
Migration Tourism & 1 & $1.2 \%$ \\
Ecotourism & 1 & $1.2 \%$ \\
Not Specified & 6 & $7.0 \%$ \\
\hline
\end{tabular}

The research topics across the extracted studies were highly diverse. Sexual behavior (16.3\%) was the most researched topic, followed by travel behavior (15.1\%), tourist risk perception (11.6\%), alcohol and substance use (8.1\%), adventure (7\%), travel medicine $(7 \%)$, and tourist decision making (5.8\%). While ten studies have considered tourist risk perception as the main subject of investigation, this is not to say that the remaining studies have not investigated risk perception. Rather, this handful of studies has devoted to the investigation of risk and its dimensions whereas others examined risk in a less explicit or indirect manner. For instance, many studies considered risk as one of the variables when examining tourist motivation, adventure tourist experience, unsafe sexual practice, or excessive alcohol consumption during holidays, just to name a few. The research topics investigated in these studies are illustrated in Table 4, ranked by importance and publication years.

Table 4. Subjects of Investigation and Years of Publication

\begin{tabular}{lccccccc}
\hline Subjects of Investigation & $1991-$ & $1996-$ & $2001-$ & $2006-$ & $2011-$ & Total & $\%$ \\
& 1995 & 2000 & 2005 & 2010 & 2015 & \\
\hline Sexual Behavior & 1 & 1 & 0 & 4 & 8 & 14 & $16.3 \%$ \\
Travel Behavior & 0 & 1 & 4 & 7 & 1 & 13 & $15.1 \%$ \\
Tourist Risk Perception & 0 & 0 & 1 & 5 & 4 & 10 & $11.6 \%$ \\
Excessive Alcohol \& Illicit Substance Use & 0 & 0 & 2 & 1 & 4 & 7 & $8.1 \%$ \\
Adventure & 0 & 1 & 1 & 2 & 2 & 6 & $7.0 \%$
\end{tabular}




$\begin{array}{llllllll}\text { Travel Medicine } & 0 & 1 & 1 & 3 & 1 & 6 & 7.0 \% \\ \text { Decision Making } & 0 & 2 & 1 & 0 & 2 & 5 & 5.8 \% \\ \text { Market Segmentation } & 0 & 0 & 0 & 1 & 2 & 3 & 3.5 \% \\ \text { Destination } & 0 & 0 & 1 & 1 & 1 & 3 & 3.5 \% \\ \text { Travel Narrative } & 0 & 0 & 1 & 1 & 1 & 3 & 3.5 \% \\ \text { Others } & 1 & 2 & 1 & 3 & 9 & 16 & 18.6 \% \\ \text { Total } & 2 & 8 & 13 & 28 & 35 & 86 & \end{array}$

Note. Excessive alcohol and illicit substance were often discussed in relation to risky sexual behavior. In market segmentation studies, risk propensity was regarded as a segmentation variable. In travel narrative studies, risk was mentioned by the research participants as an important aspect of the travel experience.

\subsection{Types of Risk and Study's Relevance to Gender}

Across these studies, risk was predominantly investigated in the forms of risk perception $(61.6 \%)$ and risk-taking behavior (29.1\%). Another stream of research focused on the determining and predicting factors (27.9\%) and consequential impacts (5.8\%) of risk perception and behavior. As presented in Table 5, 13 types of risk were identified in prior research. Health risk (45.3\%) was the most researched risk typology in existing tourist studies where gender is concerned. In particular, unsafe sexual behavior and excessive alcohol consumption were two risk dimensions of the most concerned. Physical risk (18.6\%), which encompassed personal safety, violence, and sexual harassment and assault, was the second most investigated risk typology. Several studies examined financial risk (15.1\%), such as purchase risk, theft, and gambling, while others discussed performance risk (15.1\%), which covered issues related to the destination, infrastructure, and satisfaction. Some studies did not specify the types of risk investigated. In such cases, risk was discussed as in the general perception of, and tolerance to, risk (e.g., Carr, 2001; Weaver, 2012). 
Table 5. Types of Risk

\begin{tabular}{|c|c|c|}
\hline Types of Risk & No. of Studies & $\%$ \\
\hline Health & 39 & $45.3 \%$ \\
\hline Unsafe Sexual Behavior & 18 & \\
\hline Excessive Alcohol Consumption & 10 & \\
\hline Substance Use & 8 & \\
\hline HIV Risk & 6 & \\
\hline Food Risk & 6 & \\
\hline Illness & 5 & \\
\hline Sun Exposure & 2 & \\
\hline Injury & 2 & \\
\hline Suicide & 1 & \\
\hline Physical & 16 & $18.6 \%$ \\
\hline Personal Safety & 8 & \\
\hline Violence & 2 & \\
\hline Sexual Harassment \& Assault & 2 & \\
\hline Financial & 13 & $15.1 \%$ \\
\hline Purchase Risk & 3 & \\
\hline Theft & 2 & \\
\hline Gambling & 2 & \\
\hline Performance & 13 & $15.1 \%$ \\
\hline Destination & 6 & \\
\hline Functional/Equipment & 4 & \\
\hline Satisfaction & 3 & \\
\hline Transport & 2 & \\
\hline Weather & 1 & \\
\hline Social & 10 & $11.6 \%$ \\
\hline Psychological & 8 & $9.3 \%$ \\
\hline Political/Terrorism & 7 & $8.1 \%$ \\
\hline Cultural & 7 & $8.1 \%$ \\
\hline
\end{tabular}


Flood

Hurricane

1

Adventure Risk Taking

4

$4.7 \%$

Temporal

3

$3.5 \%$

Privacy \& Data Security

2

$2.3 \%$

Legal

1

$1.2 \%$

Not Specified

4

$4.7 \%$

Note: More than one risk typology can be considered in one single study.

The relevance of gender in tourist risk research is reported in Table 6, with the trend charted against the publication years. The three categories of gender relevance were informed by Henderson and Gibson's (2013) gender scholarship framework. Gender as variable referred to studies where gender was identified as a variable to provide statistical or descriptive differences without further explanation. On the contrary, gender-focused studies interpret behavior from a gender perspective by examining the complexity of gender, such as from the perspectives of femininities, masculinities, and gender roles. Women-focused research, as indicated in the label, emphasizes exclusively on women's experiences. The majority of the extracted studies considered gender as a variable (67.4\%), even though different degrees of emphasis were assigned to this variable. Only $10.5 \%$ of the studies were gender focused, and $22.1 \%$ were women focused. Overall, an increasing number of studies have considered gender when investigating travel-related risks, and this trend has picked up since 2006. 
Table 6. Gender Relevance and Publication Years

\begin{tabular}{lccccccc}
\hline & $1991-$ & $1996-$ & $2001-$ & $2006-$ & $2011-$ & Total & $\%$ \\
& 1995 & 2000 & 2005 & 2010 & 2015 & & \\
\hline Gender as Variable & 1 & 4 & 9 & 19 & 25 & 58 & $67.4 \%$ \\
Women Focused & 1 & 2 & 2 & 7 & 7 & 19 & $22.1 \%$ \\
Gender Focused & 0 & 2 & 2 & 2 & 3 & 9 & $10.5 \%$ \\
Total & 2 & 8 & 13 & 28 & 35 & 86 & \\
\hline
\end{tabular}

\subsection{Research Methods and Theoretical Frameworks}

Table 7 presents a cross-tabulation between the methods used in the extracted literature and the study's relevance to gender. A breakdown of the research methods is presented in Table 8 . A majority of the studies reviewed (77.9\%) have preferred a quantitative methodology, with only 13 qualitative studies, five mixed-method studies, and one review paper. Studies that considered gender as one of the variables have exclusively employed a quantitative approach, with only one mixed-method exception. This is likely to be occasioned by the capacity of quantitative analysis in identifying statistical gender differences in tourist risk experience. Qualitative methodology was most valued in studies that focused on women. This observation accords with Henderson and Gibson's (2013) review of women and gender research in leisure studies, where qualitative method remains an instrumental tool in eliciting women's experience whose voices have been marginalized (Pritchard, Morgan, Ateljevic, \& Harris, 2007). 
Table 7. Methods Used to Investigate Gender and Travel Risk

\begin{tabular}{lcccc}
\hline & Quantitative & Qualitative & Mixed Methods & Review \\
\hline Study's Relevance to Gender & 57 & & & \\
Gender as Variable (58) & 5 & 1 & 2 & 1 \\
Gender Focused (9) & 5 & 12 & 2 & \\
Women Focused (19) & 67 & 13 & 5 & 1 \\
Total & & & & \\
\hline
\end{tabular}

Table 8. Methods and Research Approaches Used

\begin{tabular}{lcc}
\hline Research Methods and Approaches & No. of Studies & $\%$ \\
\hline Quantitative & 67 & $77.9 \%$ \\
Survey & 64 & \\
Secondary Data Analysis & 2 & $15.1 \%$ \\
Experimental Design & 1 & \\
Qualitative & 13 & \\
General Qualitative Methods (interviews) & 5 & \\
Ethnography & 2 & \\
Mixed of Qualitative Methods & 1 & \\
Case Study & 1 & \\
Focus Group & 1 & $5.8 \%$ \\
Phenomenology & 1 & \\
Memory Work & 1 & \\
Analysis of Travel Writings & 1 & \\
Mixed Methods & 5 & \\
Review & 1 & \\
\hline
\end{tabular}

The lack of conceptual discussion or engagement with theories was observed across the extracted studies. Across the 86 papers, 29 studies have clearly reported applications of theoretical frameworks, of which only three studies have engaged in feminist theories 
(Falconer, 2011; Little \& Wilson, 2005; Myers, 2010). Some of the common frameworks and models employed were Cohen's Tourist Role, Plog's Tourist Psychographic Model, Hofstede's Cultural Framework, Technology Acceptance Model, Sensation-seeking Scale, and Recreation Preference Scale. While these frameworks may have implications for risk, they provide a limited theoretical understanding of the concept of risk itself. This finding resonates with the criticism made by Korstanje (2009) and William and Baláž (2013) in relation to the lack of theoretical foundation in tourist risk research. A majority of the studies appeared to be framed within a positivist or post-positivist paradigm, as only three studies have claimed to operate within an interpretive framework. Reflexivity was barely observed, with Bott (2013) being the only study that was written in the first person.

\subsection{Gender-Related Findings and Explanations}

Gender differences in tourist risk experience were found in a majority of the studies $(70.9 \%)$, except for 14 studies where gender difference was not observed, and 11 studies where the difference was not discussed. In this review, the gender difference was analyzed according to Gustafson's (1998) gendered risk framework which consists of three aspects: the strength or degree of risk perceived, risk typology, and meaning associated with risk. Nearly all studies that have observed a gender difference in the degree of risk indicated that female tourists perceived a greater risk, were more risk adverse, and/or took less risk than males. The four exceptions were that male tourists faced a greater risk of being involved in a fight (Hughes et al., 2008) and committing suicide (Wray, Miller, Gurvey, Carroll, \& Kawachi, 2008), and that women reported a higher tendency of participating in unsafe sexual practices (Nemoto, Iwamoto, Morris, Yokota, \& Wada, 2007) and consuming excessive alcohol (Klunge-de Luze, de Vallière, Genton, \& Senn, 2014). Several studies found that female and male tourists varied in terms of the types of risk perceived. In particular, female tourists perceived greater 
physical risks, including violence, personal safety, and sexual harassment or assault. In the area of adventure tourism, a few studies described how risk taking is a gendered undertaking with a masculine origin (Bott, 2013; Elsrud, 2001). Many studies underlined that gender was not the only factor determining tourist risk perception; other factors such as travel group composition, tourist role, cultural background, and past experience ought to be taken into account (Carr, 2001; Chiu \& Lin, 2011; Lepp \& Gibson, 2003). As a result, variations in risk perception may exist within the same gender group. For instance, female backpackers, who seek more novelty, may perceive a lower risk than female mass tourists, who prefer familiarity (Lepp \& Gibson, 2003). Table 9 presents the breakdown of gender-related findings reported in the extracted literature.

Table 9. Gender Differences and Explanations

\begin{tabular}{|c|c|c|}
\hline & No. of Studies & $\%$ \\
\hline Gender Differences Reported/Implied* & 61 & $70.9 \%$ \\
\hline Strength of Risk & 46 & \\
\hline Women perceived a greater / took less risk than men & 42 & \\
\hline Men perceived a greater / took less risk than women & 4 & \\
\hline Types of Risk & 14 & \\
\hline Meanings of Risk & 8 & \\
\hline Explanations for Gender Difference & 36 & \\
\hline Social Factor & 23 & \\
\hline Cultural Factor & 4 & \\
\hline Physical Strength & 1 & \\
\hline Superficial Explanation & 8 & \\
\hline Gender Difference Not Found & 14 & $16.3 \%$ \\
\hline Gender Difference Not Explored & 11 & $12.8 \%$ \\
\hline
\end{tabular}


Among the 36 studies that have provided an explanation with regard to gender differences in travel risk, social was the most widely cited factor. Several authors attributed women's greater perception of risk to the socially constructed gender norms (Berdychevsky \& Gibson, 2015; Lepp \& Gibson, 2003; Qi et al., 2009). Within a patriarchal society, women are socialized to hold a weaker gender position and their bodies are constantly being policed, which contribute to women's sense of insecurity and fear of violence when using the tourism space (Berdychevsky \& Gibson, 2015; Lepp \& Gibson, 2003; Qi et al., 2009): "by virtue of their social position, female travelers are always more vulnerable to violence" (Qi et al., 2009, p. 61); "the influence of socialization whereby some females have learned not to take as many risks as their male counterparts" (Lepp \& Gibson, 2003, p. 618); "women's fear of male violence and a sense of self-consciousness in light of the sexualized gaze are frequently constructed as gendered constraints and expressions of patriarchy in women's leisure and tourism experiences” (Berdychevsky \& Gibson, 2015, p. 307).

In the case where gender difference was not found, some authors attributed the finding to the blurring gender boundary, changing gender role, and improved gender equality (Bloemhoff, 2008; Wang \& Walker, 2010), while the rest did not provide any explanation at all. Accordingly, a close investigation was conducted on the 14 studies with no gender difference reported. A number of observations were made in relation to the research design of these studies. Some of the issues emerged were: skewed sample (Hem, Iversen, \& Nysveen, 2002), limited items measuring risk (Simpson \& Siguaw, 2013), and different risk threshold applied to female and male tourists (Klunge-de Luze et al., 2014). While these observations may have partially explained the absence of gender difference in these tourist risk studies, further in-depth investigation is needed, especially in examining the changes in the gendered tourist risk perception and behavior over time. 


\section{DISCUSSION AND FUTURE DIRECTIONS}

Figure 4 maps the key findings emerged from the review. In summary, the trajectory of tourist risk and gender research is characterized by the dominance of Western samples and contexts; the lack of a gender- and risk-focused investigation and theoretical framework; the dearth of an interpretive and reflexive approach; and the preponderance of evidence of gender difference in tourist risk perception and behavior. Based on the traits and patterns observed from the review, recommendations are provided for future research.

Figure 4. Summary of Key Review Findings

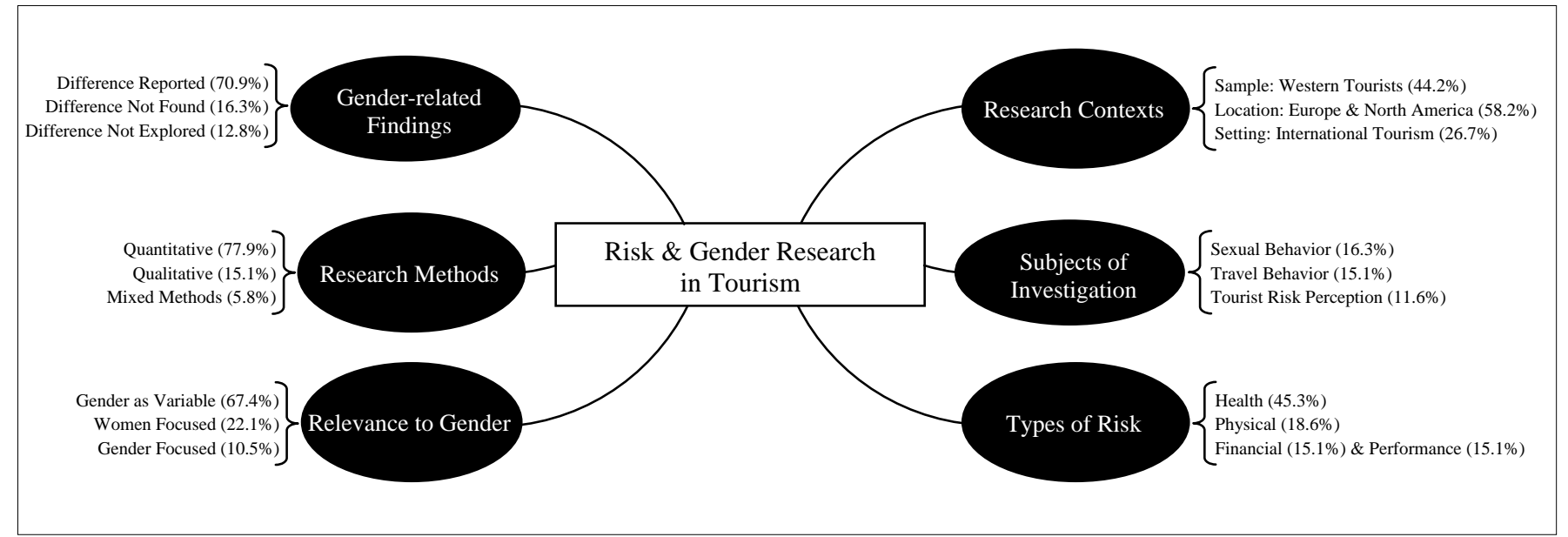

\subsection{Attending to Cultural Pluralism}

A great proportion of the studies reviewed have focused on Western tourist experience, even when the research was not carried out in a Western destination. There has been an apparent dearth of investigation on tourists from the developing and emerging nations where international travel is flourishing, such as China and India. Scholars have cautioned the appropriateness of subsuming Asian tourist experience under that of Westerners (Winter, 2009; Xu, Ding, \& Packer, 2008). As far as gender is concerned, further ramifications add to the question of generalizability of findings from a Western sample to a non-Western context, because the socially constructed gender norms and roles differ across cultural groups (Yang 
$\&$ Tavakoli, 2016). Hence, future research is encouraged to tap into the experience of nonWestern tourists by using a critical approach to examine the underlying cultural backgrounds and gender norms, and to consider their influence on tourist risk experience. An intersectional approach (Valentine, 2007) and a postcolonial perspective (Winter, 2009) that attend to cultural pluralism may provide a fitting lens to the investigation of the travel risk and the gendered Asian tourists.

\subsection{Engaging in Reflexivity}

Nearly $80 \%$ of the studies concerned have favored a positivist and quantitative approach to measure risk perception and to test hypotheses. Statistics are, undeniably, instrumental in comparing the risk perception and risk-taking propensity between female and male tourists, but the emerged discrepancy is often left unexplained or superficially explained due to the limitation of the method (e.g., Chiu \& Lin, 2011; Jalilvand \& Samiei, 2012; Lepp \& Gibson, 2003; Wang \& Walker, 2010). Of the 13 studies that have employed a qualitative method, few have employed an interpretive and reflexive approach. As a result, existing literature has provided limited understanding in relation to how women interpret the gendered travel risk, and how risk influences their travel behavior. In fact, the positivist or post-positivist dominance in research is not restricted to the risk sub-field. Tourism research, in general, has received criticisms for favoring a positivist approach, which has limited capacity in addressing the embodied and performative tourist behavior (Morgan \& Pritchard, 2005). As such, researchers who are interested in travel risk and gender are encouraged to consider a reflexive methodology such as autoethnography and memory work (Yang \& Tavakoli, 2016). A reflexive methodology may be relevant to travel risk research because the tool requires the researchers to confront the "dark side" or negative side, rather than only looking at the surface layer of travel experience (Noy, 2008; Yang, 2016). Likewise, prior research has 
demonstrated the feasibility of a reflexive approach in uncovering the social and cultural forces shaping women's travel experience (Fleming \& Fullagar, 2007; Yang, 2016). Accordingly, a reflexive methodology may be valuable in exploring the underlying meanings of risk and risk taking in tourism, and how risk works in relation to gender.

\subsection{Deepening Theoretical Understanding}

While the 86 studies reviewed have investigated travel risk to a certain extent, only 10 studies have considered risk as the main or independent subject of investigation. In fact, tourist sexual behavior was the most prevalent topic as far as gender and risk are concerned, which has also been reflected in the types of risk studied, specifically, health risk which has emerged as the most researched risk typology. Sexual behavior and gender are closely connected, but gender studies should not be limited to the discourse of sex and sexual behavior; there is more to be explored in relation to the gendered risk and the gendered tourist behavior. Furthermore, only $30 \%$ of the studies were exclusively gender or women focused, even though the literature was selected for containing "gender or female or women" in the title, abstract, and keywords. The remainder mainly treated gender as merely one of the variables, rather than deeply investigating the implication, or complication, of gender. These observations imply vast research opportunities in widening and deepening the existing understanding of gender, risk, and tourist behavior. One possible research direction is to explore the influence of social forces in shaping the gender performance of tourists in the face of risk. In addition to that, a dearth of theoretical discussion was observed. About onethird of the papers have engaged in theoretical discussion, but most of the frameworks used have not directly involved the conceptualization of risk or gendered risk. Most notably, only three studies have employed a feminist framework. It appears that existing research concerning travel risk and gender remains at a surface level. An investigation into the 
theoretical construction of travel risk and gender is highly warranted to deepen existing understanding of the topic.

The main contribution of this review has been to identify gaps in existing literature. It is important to first understand what has been discovered in order to explore what is yet to be understood. This study reveals that existing tourism research has mostly considered risk and gender superficially with limited theoretical foundations and critical discussions dedicated to in-depth understandings of the two concepts and the intertwined relationship between them. By identifying these gaps, this paper has paved the way for sound theoretical and methodological bases on which future scholars on tourism risk and gender can build. Some of these recommendations include adopting critical approaches to attend to cultural pluralism and the socio-cultural constructions of risk and gender, utilizing reflective and interpretive research methods to deepen existing understandings, and engaging in theoretical (de)constructions of risk and gender in tourism. These recommendations together with the well- and under-researched domains are illustrated in Figure 5 which contrasts Figure 1 hence highlighting the contribution of this review work. 
Figure 5. Mapping Under-researched Domains for Future Tourism Research in Gender and Risk

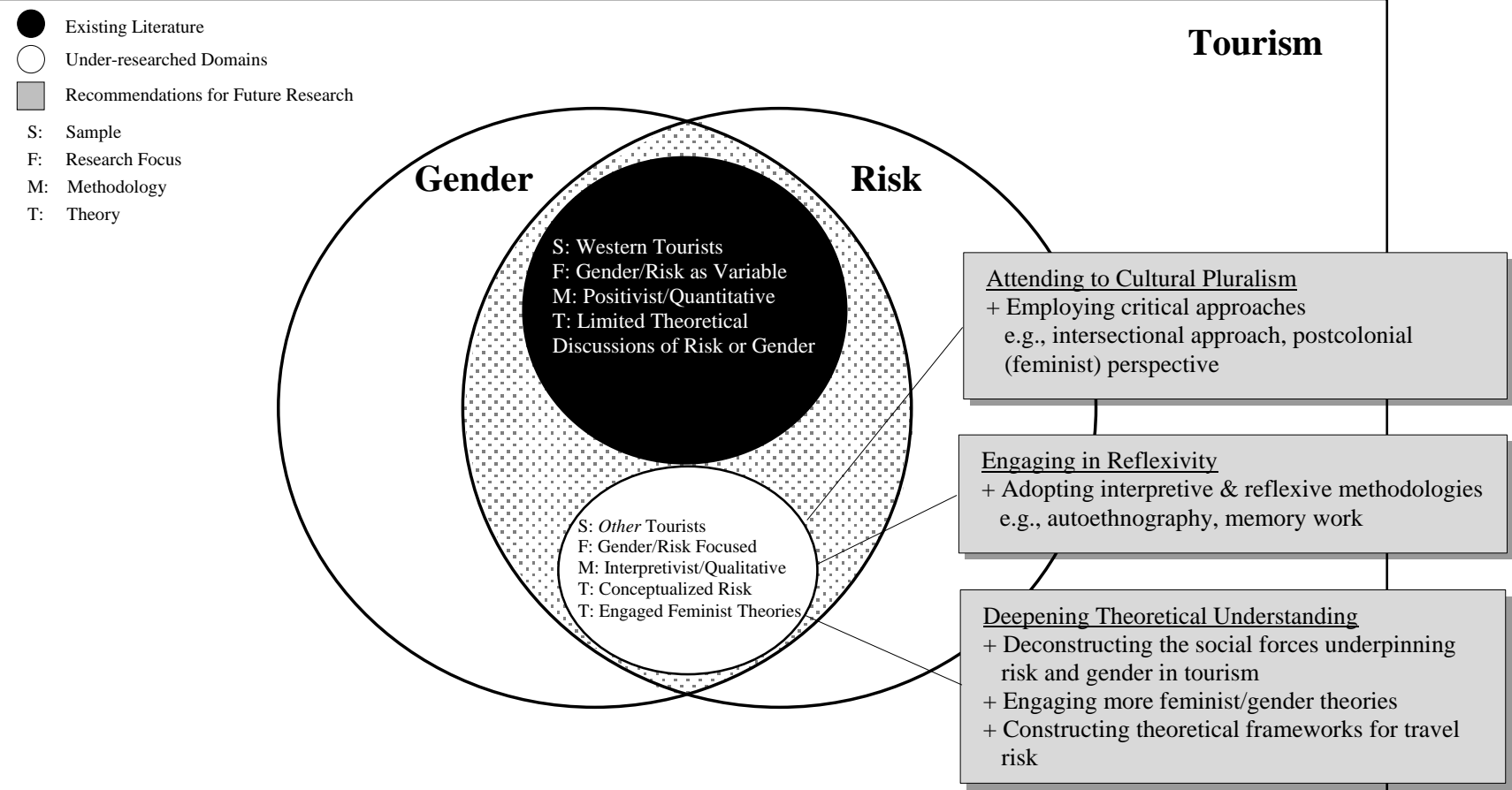

\section{CONCLUSION}

The inconsistent opinions regarding the presence of gender difference in tourist risk experience form the impetus for this study. A systematic review of existing literature shows that gender difference was found in $70 \%$ of the studies, and women's susceptibility to corporeal risk was commonly reported. While only half of these studies have attempted to provide an explanation, many have ascribed women's greater sense of fear and risk adverse attitude to the socially constructed gender roles. With that said, limited research has actually explored the association between the social forces and the gendered travel risk, such as how risk is constructed, how gender intersects with risk, and how risk-taking behavior shapes the gender performance. Besides, as the majority of the studies were conducted in a Western context, further investigation is needed to explore the influence of culture on the gendered risk perception and behavior in a tourism setting. For studies that have reported no gender difference, limitations were observed concerning the research design. Caution should be 
taken in future research when examining gender difference in travel risk, such as the sample composition and the validity of the measurement item in order to minimize bias in the research design.

Considering the steady growth of female travelers worldwide, the tourism and hospitality industry may benefit from the review findings by paying attention to women's perception of and vulnerability to certain travel risks. Some luxury hotels have incorporated female-only floors, for instance, Four Seasons Hotel in Riyadh and Georgian Court Hotel in Vancouver, while Sofitel in Luxembourg provides high floor rooms for female travelers and room service delivered exclusively by female staff (Maiden Voyage, 2014). These strategies aim to provide female travelers with a safe and secure place, though they received criticisms for being discriminatory and superficial because women still have to face the "reality" or risk when traveling outside the safe hotel rooms (Sathian, 2016). Hence, it is important for the industry to neutralize the tourism space and minimize the gendered risk. While this review was not intended to provide a comprehensive solution to solve this problem, the review findings may at least invite the industry, not just a few luxury hotels but the tourism and hospitality industry as a whole, to recognize the gender differences in risk, and to identify and subsequently address the social and physical environments that contribute to these risks.

As indicated by Petticrew and Roberts (2006), a systematic review comes with its own limitations because of its retrospective, observational, and selective nature. In line with their observation, this study was not exempted from limitations. Unlike medical terms and other highly specialized terminology, risk is a common expression in both daily language and scholarly research. As a consequence, the initial literature search resulted in a comprehensive coverage or a large amount of literature with limited relevance to the interest of the study. To 
enhance the precision of the resultant literature, the search strategy was modified and the search was restricted to three parameters: title, abstract, and keywords. As a result, studies that have considered gender differences in tourist risk experience but did not mention gender or risk in any of the three sections may have been overlooked. It is recommended that future researchers are deliberately prudent in achieving a balance between comprehensiveness and precision when conducting a systematic literature review. Furthermore, the search terms employed in this review were limited to gender and women as informed by previous literature (Figueroa-Domecq et al., 2015; Henderson \& Gibson, 2013). Future review is encouraged to include male/men and LGBTI (i.e., lesbian, gay, bisexual, transgender, and intersex) groups in the search term to consider studies that investigate the risk experience of tourists who fall in between and on the other end of the gender spectrum, and to compare the findings with this review. On a similar note, the objective of this review was to examine travel risk literature from a gender perspective; hence, other attributes were not emphasized. As suggested by the review findings, an investigation of other demographic attributes, such as age, tourist roles, and cultural backgrounds, may contribute further to existing understanding of risk in tourism. Finally, while the systematic nature of the method has made visible the review process, this study is not meant to be duplicated without careful consideration. In particular, the interpretation of the data was subjective and was influenced by the researchers' biographical background. Nevertheless, the clear reporting practice has rendered future updates and follow-up studies possible.

Despite these few limitations, this is the first study to systematically review risk literature in tourism in general and from a gender perspective in particular. This review has demonstrated the intertwined relationship between gender and travel risk and has developed a foundation for future research to build upon. In view of the growing sense of risk in 
contemporary society and the rise of the female travel market across the globe, implications were provided for the industry in recognizing the gendered nature of existing tourism space and subsequently addressing the issue.

\section{REFERENCES}

Aitchison, C. C. (2005). Feminist and gender perspectives in tourism studies: The socialcultural nexus of critical and cultural theories. Tourist Studies, 5(3), 207-224. doi: $10.1177 / 146879760507330$

Avraham, E. (2015). Destination image repair during crisis: Attracting tourism during the Arab Spring uprisings. Tourism Management, 47, 224-232. doi: 10.1016/j.tourman.2014.10.003

Beck, U. (2006). Living in the world risk society. Economy and Society, 35(3), 329-345. doi: $10.1080 / 03085140600844902$

Berdychevsky, L., \& Gibson, H. J. (2015). Phenomenology of young women's sexual risktaking in tourism. Tourism Management, 46, 299-310. doi: 10.1016/j.tourman.2014.07.008

Bloemhoff, H. J. (2008). An exploratory study of international tourists' perception of danger in Durban, Johannesburg and Cape Town. South African Journal for Research in Sport Physical Education and Recreation, 30(1), 1-13.

Bond, M. (2015). Women travel statistics explained by travel expert. Retrieved from http://gutsytraveler.com/women-travel-statistics-2/

Bott, E. (2013). New heights in climbing and tourism: Jordan's Wadi Rum. Journal of Tourism and Cultural Change, 11(1-2), 21-34. doi: 10.1080/14766825.2013.768253

Butler, J. (1990). Gender trouble: Feminism and the subversion of identity. New York, NY: Routledge. 
Carr, N. (2001). An exploratory study of gendered differences in young tourists perception of danger within London. Tourism Management, 22(5), 565-570. doi: 10.1016/S02615177(01)00014-0

Cater, C. I. (2006). Playing with risk? Participant perceptions of risk and management implications in adventure tourism. Tourism Management, 27(2), 317-325. doi: 10.1016/j.tourman.2004.10.005

Chang, S.-Y. (2009). Australians' holiday decisions in China: A study combining noveltyseeking and risk-perception behaviors. Journal of China Tourism Research, 5(4), 364387. doi: 10.1080/19388160903382533

Chiu, S.-P., \& Lin, S.-Y. (2011). Study on risk perceptions of international tourists in India. African Journal of Business Management, 5(7), 2742-2752. doi: 10.5897/AJBM10.1099

Dickson, T., \& Dolnicar, S. (2004, February 10-13). No risk, no fun: The role of perceived risk in adventure tourism. Paper presented at the CAUTHE 2004: Creating Tourism Knowledge, Brisbane, Australia.

Durko, A. M., \& Petrick, J. F. (2013). Family and relationship benefits of travel experiences: A literature review. Journal of Travel Research, 52(6), 720-730. doi: $10.1177 / 0047287513496478$

Elsrud, T. (2001). Risk creation in traveling: Backpacker adventure narration. Annals of Tourism Research, 28(3), 597-617. doi: 10.1016/S0160-7383(00)00061-X

Enloe, C. (1989). Bananas, beaches, and bases: Making feminist sense of international politics. Berkeley, CA: University of California Press.

Falconer, E. (2011). Risk, excitement and emotional conflict in women's travel narratives. Recreation and Society in Africa, Asia and Latin America, 1(2). 
Fernández, M., Pena-Boquete, Y., \& Pereira, X. (2009). Labor conditions in the Spanish hotels and restaurants industry. Tourism Analysis, 14(3), 293-312. doi: $10.3727 / 108354209789705039$

Figueroa-Domecq, C., Pritchard, A., Segovia-Pérez, M., Morgan, N., \& Villacé-Molinero, T. (2015). Tourism gender research: A critical accounting. Annals of Tourism Research, 52(0), 87-103. doi: 10.1016/j.annals.2015.02.001

Fleming, C., \& Fullagar, S. (2007). Reflexive Methodologies: An autoethnography of the gendered performance of sport/management. Annals of Leisure Research, 10(3-4), 238-256. doi: 10.1080/11745398.2007.9686765

Foley, C. (2015). The art of wasting time: Sociability, friendship, community and holidays. Leisure Studies. doi: 10.1080/02614367.2015.1055296

Giddens, A. (1991). Modernity and self-identity: Self and society in the late modern age. California, CA: Stanford University Press.

Graburn, N. H. H., \& Jafari, J. (1991). Introduction: Tourism social science. Annals of Tourism Research, 18(1), 1-11. doi: 10.1016/0160-7383(91)90035-A

Green, E., \& Singleton, C. (2006). Risky bodies at leisure: Young women negotiating space and place. Sociology, 40(5), 853-871. doi: 10.1177/0038038506067510

Gross, M. J., Gao, H., \& Huang, S. (2013). China hotel research: A systematic review of the English language academic literature. Tourism Management Perspectives, 6, 68-78. doi: 10.1016/j.tmp.2012.11.004

Gustafson, P. E. (1998). Gender differences in risk perception: Theoretical and methodological perspectives. Risk Analysis, 18(6), 805-811. doi: 10.1111/j.15396924.1998.tb01123.x 
Harris, C., \& Wilson, E. (2007). Travelling beyond the boundaries of constraint: Women, travel and empowerment. In A. Pritchard, N. Morgan, I. Ateljevic \& C. Harris (Eds.), Tourism \& gender: Embodiment, sensuality and experience. Oxfordshire, UK: CABI.

Hem, L. E., Iversen, N. M., \& Nysveen, H. (2002). Effects of ad photos portraying risky vacation situations on intention to visit a tourist destination: Moderating effects of age, gender and nationality. Journal of Travel \& Tourism Marketing, 13(4), 1. doi: 10.1300/J073v13n04_01.

Henderson, K. A., \& Gibson, H. J. (2013). An integrative review of women, gender, and leisure: Increasing complexities. Journal of Leisure Research, 45(2), 115-135.

Hughes, K., Bellis, M. A., Calafat, A., Juan, Schnitzer, S., \& Anderson, Z. (2008). Predictors of violence in young tourists: a comparative study of British, German and Spanish holidaymakers. European Journal of Public Health, 18(6), 569-574. doi: 10.1093/eurpub/ckn080

Jalilvand, M. R., \& Samiei, N. (2012). Perceived risks in travelling to the Islamic Republic of Iran. Journal of Islamic Marketing, 3(2), 175-189. doi: 10.1108/17590831211232573

Jordan, F., \& Gibson, H. (2005). "We're not stupid...But we'll not stay home either": Experiences of solo women travelers. Tourism Review International, 9(2), 195-211. doi: $10.3727 / 154427205774791663$

Khoo-Lattimore, C., \& Mura, P. (Eds.). (2016). Asian genders in tourism. Bristol, UK: Channel View.

Khoo-Lattimore, C., \& Wilson, E. (Eds.). (2016). Women and travel: Historical and contemporary perspectives. Oakville, Canada: Apple Academic Press.

Klunge-de Luze, C., de Vallière, S., Genton, B., \& Senn, N. (2014). Observational study on the consumption of recreational drugs and alcohol by Swiss travelers. Bmc Public Health, 14, 1199. doi: 10.1186/1471-2458-14-1199 
Korstanje, M. E. (2009). Re-visiting risk perception theory in the context of travel. e-Review of Tourism Research, 7(4), 68-81.

Kovari, I., \& Zimanyi, K. (2011). Safety and security in the age of global tourism (The changing role and conception of safety and security in tourism). APSTRACT: Applied Studies in Agribusiness and Commerce, 5(3-4), 59-61.

Kozak, M., Crotts, J. C., \& Law, R. (2007). The impact of the perception of risk on international travellers. International Journal of Tourism Research, 9(4), 233-242. doi: $10.1002 /$ jtr.607

Laurendeau, J. (2008). "Gendered risk regimes": A theoretical consideration of edgework and gender. Sociology of Sport Journal, 25, 293-309.

Lepp, A., \& Gibson, H. (2003). Tourist roles, perceived risk and international tourism. Annals of Tourism Research, 30(3), 606-624. doi: 10.1016/S0160-7383(03)00024-0

Little, D. E., \& Wilson, E. (2005). Adventure and the gender gap: Acknowledging diversity of experience. Society and Leisure, 28(1), 185-208. doi: $10.1080 / 07053436.2005 .10707676$

Lupton, D. (2013). Risk (2nd ed.). Oxon, UK: Routledge.

Maiden Voyage. (2014). Female friendly hotels. Retrieved from http://www.maidenvoyage.com/Hotels.aspx

Mair, J., Ritchie, B. W., \& Walters, G. (2014). Towards a research agenda for post-disaster and post-crisis recovery strategies for tourist destinations: A narrative review. Current Issues in Tourism, 1-26. doi: 10.1080/13683500.2014.932758

Mays, N., Pope, C., \& Popay, J. (2005). Systematically reviewing qualitative and quantitative evidence to inform management and policy-making in the health field. Journal of Health Services Research \& Policy, 10(suppl 1), 6-20. doi: $10.1258 / 1355819054308576$ 
Mitchell, V. W., \& Greatorex, M. (1993). Risk perception and reduction in the purchase of consumer services. The Service Industries Journal, 13(4), 179-200. doi: $10.1080 / 02642069300000068$

Moher, D., Liberati, A., Tetzlaff, J., \& Altman, D. G. (2009). Preferred Reporting Items for Systematic Reviews and Meta-Analyses: The PRISMA Statement. Annals of Internal Medicine, 151(4), 264-269. doi: 10.7326/0003-4819-151-4-200908180-00135

Morgan, N., \& Pritchard, A. (2005). On souvenirs and metonymy: Narratives of memory, metaphor and materiality. Tourist Studies, 5(1), 29-53. doi: $10.1177 / 1468797605062714$

Mullen, J. (2016, June 29). Istanbul airport attack: A fresh blow to tourism in Turkey. CNN. Retrieved from http://money.cnn.com/2016/06/29/news/economy/istanbul-airportattack-turkey-tourism-crisis/

Myers, L. (2010). Women travellers' adventure tourism experiences in New Zealand. Annals of Leisure Research, 13(1-2), 116-142. doi: 10.1080/11745398.2010.9686841

Nemoto, T., Iwamoto, M., Morris, A., Yokota, F., \& Wada, K. (2007). Substance use and sexual behaviors among Japanese tourists, students, and temporary workers in Honolulu, Hawaii. AIDS Education and Prevention, 19(1), 68-81.

Newton-Small, J. (2015, November 23). The cost of the Paris attacks. Time. Retrieved from http://time.com/4123827/paris-attacks-tourism/

Noy, C. (2008). The poetics of tourist experience: An autoethnography of a family trip to Eilat. Journal of Tourism and Cultural Change, 5(3), 141-157. doi: 10.2167/jtcc085.0

Olstead, R. (2011). Gender, space and fear: A study of women's edgework. Emotion, Space and Society, 4(2), 86-94. doi: 10.1016/j.emospa.2010.12.004

Oxford Disctionaries. (2016). Adventuress. $\quad$ Retrieved from http://www.oxforddictionaries.com/definition/american_english/adventuress 
Park, K., \& Reisinger, Y. (2010). Differences in the Perceived Influence of Natural Disasters and Travel Risk on International Travel. Tourism Geographies, 12(1), 1-24. doi: $10.1080 / 14616680903493621$

Petticrew, M., \& Roberts, H. (2006). Systematic reviews in the social sciences: A practical guide. Malden, MA: Blackwell.

Pickering, C., \& Byrne, J. (2014). The benefits of publishing systematic quantitative literature reviews for $\mathrm{PhD}$ candidates and other early-career researchers. Higher Education Research \& Development, 33(3), 534-548. doi: 10.1080/07294360.2013.841651

Pickering, C., Grignon, J., Steven, R., Guitart, D., \& Byrne, J. (2015). Publishing not perishing: How research students transition from novice to knowledgeable using systematic quantitative literature reviews. Studies in Higher Education, 40(10), 17561769. doi: 10.1080/03075079.2014.914907

Pritchard, A., \& Morgan, N. J. (2000). Privileging the male gaze: Gendered tourism landscapes. Annals of Tourism Research, 27(4), 884-905. doi: 10.1016/S01607383(99)00113-9

Pritchard, A., Morgan, N., Ateljevic, I., \& Harris, C. (2007). Editors' introduction: Tourism, gender, embodiment and experience. In A. Pritchard, N. Morgan, I. Ateljevic \& C. Harris (Eds.), Tourism and gender: Embodiment, sensuality, and experience (pp. 112). Oxfordshire, UK: CABI.

Qi, C. X., Gibson, H. J., \& Zhang, J. J. (2009). Perceptions of risk and travel intentions: The case of China and the Beijing Olympic Games. Journal of Sport \& Tourism, 14(1), 43-67. doi: 10.1080/14775080902847439

Quintal, V. A., Lee, J. A., \& Soutar, G. N. (2010). Risk, uncertainty and the theory of planned behavior: A tourism example. Tourism Management, 31(6), 797-805. doi: 10.1016/j.tourman.2009.08.006 
Reichel, A., Fuchs, G., \& Uriely, N. (2007). Perceived risk and the non-institutionalized tourist role: The case of Israeli student ex-backpackers. Journal of Travel Research, 46(2), 217-226. doi: 10.1177/0047287507299580

Sathian, S. (2016). Hotels should create women-only floors. Retrieved from http://www.ozy.com/immodest-proposal/hotels-should-create-women-onlyfloors $/ 41448$

Simpson, P. M., \& Siguaw, J. A. (2013). Lifestyle and satisfaction of winter migrants. Tourism Management Perspectives, 5, 18-23. doi: 10.1016/j.tmp.2012.09.005

Valentine, G. (2007). Theorizing and researching intersectionality: A challenge for feminist geography. The Professional Geographer, 59(1), 10-21. doi: 10.1111/j.14679272.2007.00587.x

Wang, X., \& Walker, G. J. (2010). A comparison of Canadian and Chinese university students' travel motivations. Leisurel Loisir, 34(3), 279-293. doi: $10.1080 / 14927713.2010 .521318$

Weaver, D. B. (2012). Psychographic insights from a South Carolina protected area. Tourism Management, 33(2), 371-379. doi: 10.1016/j.tourman.2011.04.006

Williams, A. M., \& Baláž, V. (2013). Tourism, risk tolerance and competences: Travel organization and tourism hazards. Tourism Management, 35, 209-221. doi: 10.1016/j.tourman.2012.07.006

Wilson, E., \& Little, D. E. (2005). A 'relative escape'? The impact of constraints on women who travel solo. Tourism Review International, 9(2), 155-175. doi: $10.3727 / 154427205774791672$

Wilson, E., \& Little, D. E. (2008). The solo female travel experience: Exploring the 'geography of women's fear'. Current Issues in Tourism, 11(2), 167-186. doi: $10.2167 / \operatorname{cit} 342.0$ 
Winter, T. (2009). Asian tourism and the retreat of Anglo-Western centrism in tourism theory. Current Issues in Tourism, 12(1), 21-31. doi: 10.1080/13683500802220695

Wittig, M. (1983). The point of view: Universal of particular. Feminist Issues, 3(2), 63-69.

Wray, M., Miller, M., Gurvey, J., Carroll, J., \& Kawachi, I. (2008). Leaving Las Vegas: Exposure to Las Vegas and risk of suicide. Social Science \& Medicine, 67(11), 18821888. doi: 10.1016/j.socscimed.2008.09.002

Xu, H., Ding, P., \& Packer, J. (2008). Tourism research in China: Understanding the unique cultural contexts and complexities. Current Issues in Tourism, 11(6), 473-491. doi: $10.1080 / 13683500802475737$

Yang, E. C. L. (2016). Risk perception of Asian solo female travelers: An autoethnographic approach. In C. Khoo-Lattimore \& E. Wilson (Eds.), Women and travel: Trends, journeys and experiences. Bristol, UK: Channel View.

Yang, E. C. L., \& Nair, V. (2015). Tourism at risk: A review of risk and perceived risk in tourism. Asia-Pacific Journal of Innovation in Hospitality and Tourism, 3(2), 1-21. doi: 10.7603/s40930-014-0013-z

Yang, E. C. L., Sharif, S. P., \& Khoo-Lattimore, C. (2015). Tourists' risk perception of risky destinations: The case of Sabah's eastern coast. Tourism and Hospitality Research. doi: $10.1177 / 1467358415576085$

Yang, E. C. L., \& Tavakoli, R. (2016). “Doing” tourism gender research in Asia: An analysis of authorship, research topic, and methodology. In C. Khoo-Lattimore \& P. Mura (Eds.), Tourism and Asian genders. Bristol, UK: Channel View.

Yang, H., \& Cheung, C. (2010). A review of English literature on ecotourism research in China. Journal of China Tourism Research, 6(4), 370-382. doi: $10.1080 / 19388160.2010 .527574$ 